S U M A R I O

I. Dossier: Literatura ARgENTINA

LAURA JuÁrez, Arlt y la polémica sobre la novela ........................... ILSE Logie y Julia Romero, Extranjeridad: lengua y traducción en la obra de

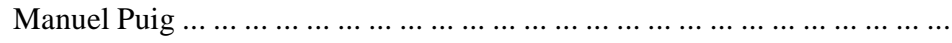

María Silvina Persino, Memoriales, museos, monumentos: la articulación de una memoria pública en la Argentina posdictatorial ........................

M. Edurne Portela, Cicatrices del trauma: cuerpo, exilio y memoria en Una sola

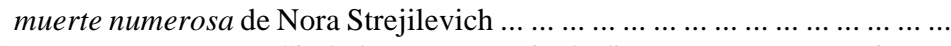

Claudia Darrigrandi, Ciudad, cuerpo y traje: la flâneuse en Buenos Aires ...

Miriam V. GÁrate, Crítica cinematográfica y ficción en Horacio Quiroga .......

\title{
II. EsTUDIOS
}

Sergio Rivera-Ayala, La “reconquista” de América en la Historia antigua de México de Francisco Javier Clavijero ...................................

Cecilia Rodríguez LenMann, La política en el guardarropa. Las crónicas de moda

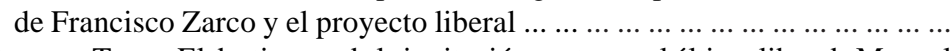

BENIGNo TRIgo, El destiempo de la invitación: en torno al último libro de Manuel Ramos Otero $\ldots \ldots \ldots \ldots \ldots \ldots \ldots \ldots \ldots \ldots \ldots \ldots \ldots \ldots \ldots \ldots \ldots \ldots \ldots \ldots \ldots$

Wilfredo Hernández, Contradiscurso y paratextualidad en Elegía sin nombre

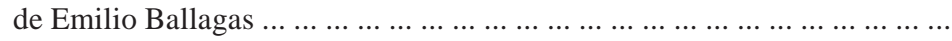

Pedro Pereira, “Um livro maior do que a gente”: sugestões para uma releitura dos prefácios de Tutaméia de João Guimarães Rosa ... ... ................

Gastón Alzate, El extremismo de la lucidez: San Fernando Vallejo ............

Santa Arias, De Fray Servando Teresa de Mier a Juan Bautista Muñoz: la disputa guadalupana en vísperas de la independencia ...................

EnRIQUe CoRTEz, La aventura fantástica: la representación como conflicto en Julio Ramón Ribeyro ...................................................

Irene Gómez Castellano, "Rodeada de puntos suspensivos”: los usos del espacio en Oxido de Carmen de Ana María del Río 


\section{ENTREVISTAS}

Eleni Kefala, Diez preguntas a Noé Jitrik ... ........................... NÉstor E. Rodríguez, Impredecible oficio el de la maravilla: entrevista al escritor

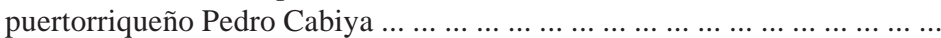

IV. NECROLÓGICA

Mary K. Addis, In Memoriam: Lizando Chávez Alfaro (Bluefields 1929Managua 2006)

\section{RESEÑAS}

Angel A. Rivera sobre Christopher Schmidt-Nowara, The Conquest of History: Spanish Colonialism National Histories in the Nineteenth Century ............ Denise Galarza Sepúlveda sobre Ruth Hill, Hierarchy, Commerce and Fraud

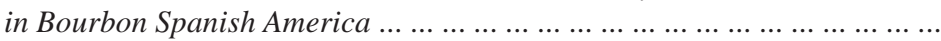

Eyda M. Merediz sobre Marina Pérez de Mendiola, ed., Going Transatlantic:

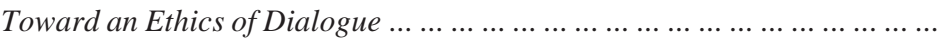
Ana Cecilia Olmos sobre Viviana Gelado, Poéticas da transgressão: vanguarda e cultura popular nos anos vinte na América Latina ... ... ................... Jossianna Arroyo sobre Jerome C. Branche, Colonialism and Race in Luso-

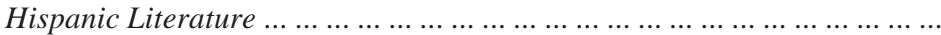

